\title{
Design and fabrication of Bragg grating based DFB fiber lasers operating above 1610
} $\mathrm{nm}$

Varming, Poul; Lauridsen, Vibeke Claudia; Povlsen, Jørn Hedegaard; Jensen, Jesper Bo; Kristensen, Martin; Palsdottir, Bera

Published in:

Optical Fiber Communication Conference

Link to article, DOI:

10.1109/OFC.2000.868509

Publication date:

2000

Document Version

Publisher's PDF, also known as Version of record

Link back to DTU Orbit

Citation (APA):

Varming, P., Lauridsen, V. C., Povlsen, J. H., Jensen, J. B., Kristensen, M., \& Palsdottir, B. (2000). Design and fabrication of Bragg grating based DFB fiber lasers operating above $1610 \mathrm{~nm}$. In Optical Fiber Communication Conference (Vol. 3, pp. 17-19). https://doi.org/10.1109/OFC.2000.868509

\section{General rights}

Copyright and moral rights for the publications made accessible in the public portal are retained by the authors and/or other copyright owners and it is a condition of accessing publications that users recognise and abide by the legal requirements associated with these rights.

- Users may download and print one copy of any publication from the public portal for the purpose of private study or research.

- You may not further distribute the material or use it for any profit-making activity or commercial gain

- You may freely distribute the URL identifying the publication in the public portal 


\title{
Design and fabrication of Bragg grating based DFB fiber lasers operating above $1610 \mathrm{~nm}$
}

\author{
Poul Varming, Vibeke C. Lauridsen, Jørn H. Povlsen, Jesper B. Jensen and Martin Kristensen \\ Research Center COM, Technical University of Denmark, Building 349, DK-2800 Lyngby, Denmark \\ Phone: +45 45253775, Fax: +45 45936581,Email: pv@com.dtu.dk \\ Bera Pálsdóttir \\ Lucent Technologies Denmark, Priorparken 680, DK-2605 Brøndby, Denmark, bpalsdottir@lucent.com
}

The erbium doped distributed feedback (DFB) fiber laser with an UV induced phase-shift was introduced in 1995 [1]. It provides a stable, single-mode laser for applications in optical communication [2,3]. It combines a high signal to noise ratio, robust single-mode operation and narrow line-width $(\sim 1 \mathrm{kHz})$.

Optical amplifiers and sources in the L-band $(1570 \mathrm{~nm}-1610 \mathrm{~nm})$ have recently attracted a lot of attention for optical networks. L-band components increase the capacity and flexibility of WDM systems by increasing the available bandwidth. Further, L-band components enable WDM transmission on installed dispersion shifted fibers, since at the high wavelengths there is sufficient dispersion to suppress four-wave mixing generated channel crosstalk [4]. The development of erbium doped fiber amplifiers for the L-band suggests the erbium doped DFB fiber laser as a promising candidate to provide a high quality source covering the wavelength range from $1530-1615 \mathrm{~nm}$.

We use a numerical model [5] to optimize the DFB laser design for L-band and report experimental results obtained with DFB fiber lasers at $1608 \mathrm{~nm}$ and $1613 \mathrm{~nm}$. We find that the intrinsic fiber loss is an important parameter, which limits the obtainable laser output power and determine the optimum value of the Bragg grating strength for a fixed length. UV induced loss, which depends on the wavelength and the intensity of the UV beam as well as the fiber design and dopants normally dominate the intrinsic loss. Finally we investigate the temperature dependence of a laser.

The numerical model is based on the steady state rate equations for $\mathrm{Er}^{3+}$-ions in combination with coupled mode equations between the forward and the backward propagating DFB-laser modes. The model includes a fast varying spatial hole burning caused by the fast varying interference pattern between the forward and backward laser modes and a slowly varying hole burning caused by the spatial variation of the laser field intensity. The intrinsic fiber loss is included, but the model does not include exited state absorption (ESA) between the ${ }^{4} \mathrm{I}_{13 / 2}$ and ${ }^{4} \mathrm{I}_{9 / 2}$ (800nm pump band) energy levels. The ESA is negligible around $1550 \mathrm{~nm}$ but becomes significant around $1610 \mathrm{~nm}$.

In the following we consider fiber gratings pumped with $60 \mathrm{~mW}$ at $980 \mathrm{~nm}$. We use the room temperature emission and absorption cross sections and the erbium concentration $\left(\rho=1.18 \cdot 10^{25} \mathrm{~m}^{-3}\right)$ from the fiber used for the $1608 \mathrm{~nm}$ DFB fiber lasers presented later in the paper. A discrete phase-shift of $\pi$ is positioned at the center of the grating, allowing the laser to operate at the Bragg wavelength, $\lambda_{\mathrm{B}}$.

Figure 1 (a) and (b) shows the DFB laser output power as a function of the intrinsic loss parameter, $\alpha$, calculated for $\lambda_{B}=1608 \mathrm{~nm}$, different values of the gratings coupling coefficient, $\kappa$ (proportional to the index modulation), and for Bragg grating lengths, $L$, of 50 and $100 \mathrm{~mm}$. The figure shows that in the lossless case the output power increases with $\kappa L$, but as $\kappa$ increases the laser becomes very sensitive to the intrinsic fiber loss, and consequently there exist an optimum value $\kappa L \leq 10$ that will result in the highest output power for a realistic value of the loss [6]. When $\kappa L$ increases, the Q-value of the cavity also increases. Therefore the cavity lifetime of a photon increases and when the cavity lifetime becomes comparable to the absorption lifetime $\alpha / \mathrm{c}$ a significant fraction of the photons will be lost by intrinsic absorption. Further, numerical calculations show that the maximum obtainable output power increases linearly 


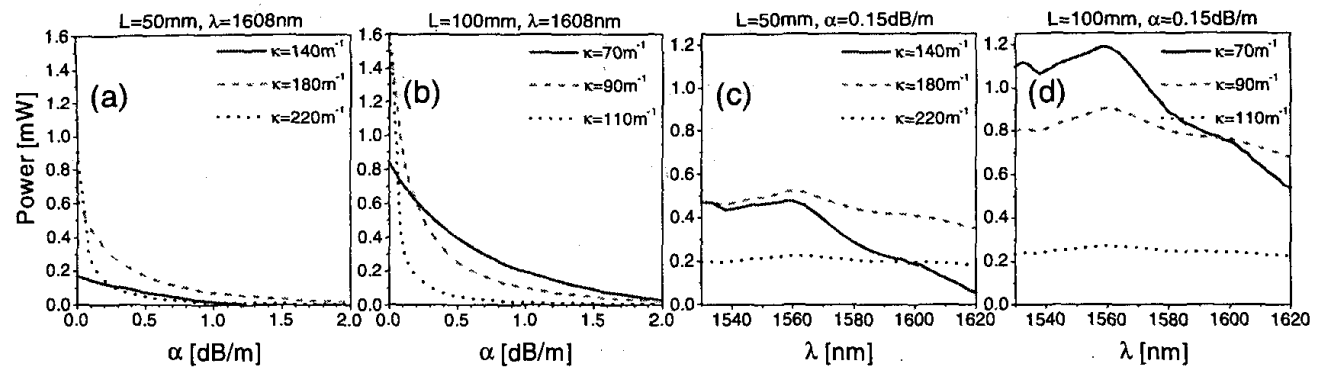

Fig. 1: DFB laser output power at $1608 \mathrm{~nm}$ as a function of the intrinsic loss parameter, calculated for different values of the coupling coefficient, $\kappa$, and for Bragg grating lengths of (a) $L=50 \mathrm{~mm}$ and (b) $L=100 \mathrm{~mm}$. Calculated laser output power as a function of the lasing wavelength. (c) $L=50 \mathrm{~mm}$. (d) $L=100 \mathrm{~mm}$.

with the grating length, and for a fixed value of the intrinsic loss the maxima are found for a constant value of $\kappa L$ [5]. This means that the optimum value of the coupling coefficient is $\kappa_{\text {opt }}=K / L$, where the constant $K$ depends on the intrinsic fiber loss, the erbium concentration and the power confinement factor.

In figure 1 (c) and (d) the fiber laser output power is shown as a function of the lasing wavelength for Bragg grating lengths, $L$, of 50 and $100 \mathrm{~mm}$, assuming an intrinsic loss of $0.15 \mathrm{~dB} / \mathrm{m}$. The result suggest that lasing is possible above $1600 \mathrm{~nm}$, but the output power at the highest wavelengths may be overestimated due to the influence of ESA. The shape of the curves depends mainly on the $\kappa L$ product, although the influence of the intrinsic loss increases, as the grating becomes longer. For a $50 \mathrm{~mm}$ long grating a very high coupling coefficient $\left(\kappa \sim 180 \mathrm{~m}^{-1}\right)$ provides the highest output power around $1600 \mathrm{~nm}$. In contrast, a rather low coupling coefficient $\left(\kappa-90 \mathrm{~m}^{-1}\right)$ provides the highest output power around $1600 \mathrm{~nm}$ when a $100 \mathrm{~mm}$ long Bragg grating is used.

Encouraged by the numerical results we conducted experiments using two different erbium doped fibers. The first fiber was the erbium doped fiber described in the model above, whereas the second fiber has much higher gain with peak absorption of $62 \mathrm{~dB} / \mathrm{m}$ at $1530 \mathrm{~nm}$. Lasing of $100 \mathrm{~mm}$ long lasers above $1600 \mathrm{~nm}$ was obtained for both fibers and figure 2 shows the corresponding lasing spectra. For the first fiber the best lasing was obtained for $\mathrm{k}=90 \mathrm{~m}^{-1}$, while an unstable lasing was obtained for $\kappa=100 \mathrm{~m}^{-1}$. The difficulty of optimizing the lasers phase-shift was severely increased by the UV induced loss. Stable single-polarization and single-mode lasing was observed after annealing the laser at $200^{\circ} \mathrm{C}$, which decreases the UV induced intrinsic loss. The output power of $25 \mu \mathrm{W}(60 \mathrm{~mW}$ of $980 \mathrm{~nm}$ pump) is around $16 \mathrm{~dB}$ less than we can obtain around $1550 \mathrm{~nm}$. The pump threshold is $16 \mathrm{~mW}$. In the second fiber we could easily obtain lasing with $\mathrm{k}=85 \mathrm{~m}^{-1}$ and $95 \mathrm{~m}^{-1}$. Single-mode operation was achieved after inducing the phase-shift. After annealing, the output power was $0.62 \mathrm{~mW}$ (60 $\mathrm{mW}$ of $980 \mathrm{~nm}$ pump). The pump
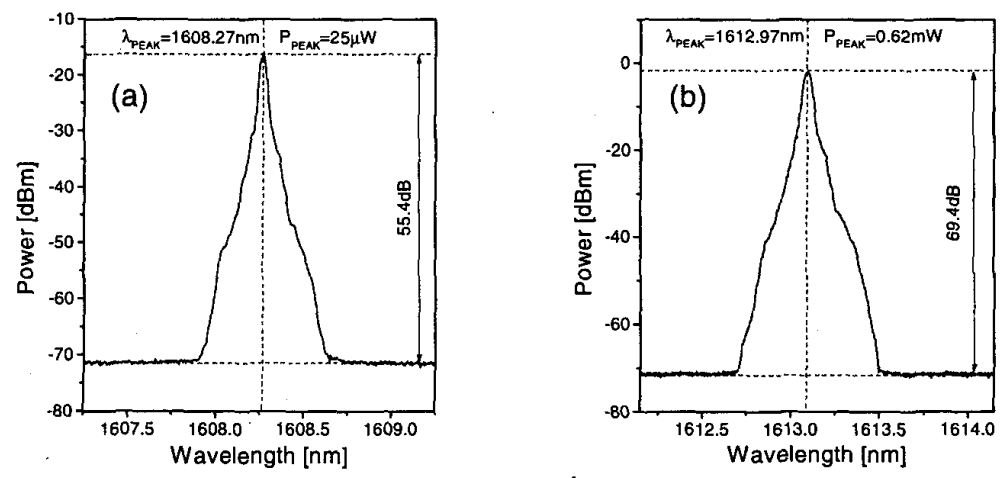

Fig. 2: Lasing spectrum of DFB fiber lasers. (a) $k=90 \mathrm{~m}^{-1}, L=100 \mathrm{~mm}, 60 \mathrm{~mW}$ of $980 \mathrm{~nm}$ pump, fiber 1 . (b) $\mathrm{K}=95 \mathrm{~m}^{-1}, L=100 \mathrm{~mm}, 60 \mathrm{~mW}$ of $980 \mathrm{~nm}$ pump, fiber 2 

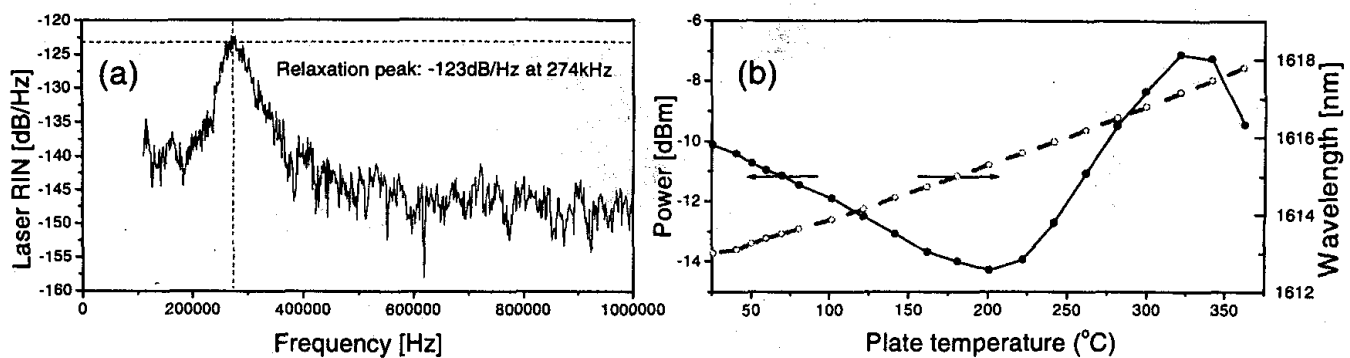

Fig. 3: (a) Laser RIN spectrum, (b) Temperature tuning characteristics

threshold is around $3 \mathrm{~mW}$. The difference between the lasers with $\kappa=85 \mathrm{~m}^{-1}$ and $95 \mathrm{~m}^{-1}$ is.very small, and the sensitivity to the magnitude of the induced phase-shift and the laser packaging made it impossible to distinguish which is better.

Figure $3 \mathrm{a}$ show the noise spectrum of the laser. The relative intensity noise (RIN) of the laser is -123 $\mathrm{dB} / \mathrm{Hz}$ at the relaxation peak $(273 \mathrm{kHz})$ and above $1 \mathrm{MHz}$ the laser $\mathrm{RIN}$ is below the measurement limit of the HP Lightwave Analyzer.

The laser operation at high temperature was investigated by placing it on a heating plate. The temperature was kept constant for 10 minutes at each step, measuring a set of laser wavelength and corresponding output power. The result is shown in figure $3 \mathrm{~b}$. We observe a linear wavelength shift with temperature and reach $1618 \mathrm{~nm}$ at $360^{\circ} \mathrm{C}$. The output power shows a complicated behavior with temperature. Below $200^{\circ} \mathrm{C}$ we believe this is due to various changes in the gain spectrum. Above $320^{\circ} \mathrm{C}$ the power decreases as the grating is becoming significantly weaker and thermo-mechanical loss from the fiber coating and packaging increases.

In conclusion we have shown that it is possible to manufacture DFB fiber lasers with wavelengths at least up to $1618 \mathrm{~nm}$. Numerical simulations show that it is possible to increase the output power by using a longer Bragg grating for the laser cavity. However, for long lasers, the output power depends strongly on the intrinsic fiber loss, which makes a moderate coupling coefficient of the Bragg grating the optimum choice for long lasers. We have presented two fiber lasers using different erbium doped fibers. The lasers operate at $1608 \mathrm{~nm}$ and $1613 \mathrm{~nm}$ respectively and both provide stable single-mode and single-polarization lasing as needed for sources used in L-band communication.

\section{References:}

[1] P. Varming, J. Hübner and M. Sejka, "Erbium doped fibre DFB laser with permanent $\pi / 2$ phase-shift induced by UV postprocessing", IOOC'95, Tech. Digest, vol. 5, PD1-3, 1995

[2] H. N. Poulsen, P. Varming A. Buxens, A. T. Clausen, I. Muñoz, P. Jeppesen, C. V. Poulsen, J. E. Pedersen and L. Eskildsen, "1607 nm DFB fibre laser for optical communication in the L-band", ECOC'99, Tech. Digest, paper Mo B2.1, 1999

[3] M. Ibsen, A. Fu, H. Geiger and R. I. Laming, "Fibre DFB lasers in 4x10 Gbit/s WDM link with a single sinc-sampled fibre grating dispersion compensator", ECOC'98, Tech. Digest, vol. 3, pp. 109-111, 1998

[4] T. Sakamoto, J. Kani, M. Jinno, S. Aisawa, M. Fukui, M. Yamada and K. Oguchi, "Wide wavelength band (1535-1560 nm and $1574-1600 \mathrm{~nm}), 28 \times 10 \mathrm{Gbit} / \mathrm{s}$ WDM transmission over $320 \mathrm{~km}$ dispersion-shifted fibre", Electron. Lett., vol. 34, no. 4, pp. 392-394, 1998

[5] V.C. Lauridsen, J.H. Povlsen and P. Varming, "Optimising erbium-doped DFB fibre laser length with respect to maximum output power", Electron. Lett., vol. 35, no. 4, pp. 300-302, 1999

[6] G. Meltz and W.W. Morey, "Bragg grating formation and germanosilicate fiber photosensitivity", Proc. SPIE, vol. 1516, pp. 185-199, 1991 